Subpial cerebral siderosis. Neurology 1962;12:108-13.

13 Tomlinson BE, Walton JN. Superficial haemosiderosis of the central nervous system. J Neurol Neurosurg Psychiatry 1964;27:332-9.

14 Braham J, Wolman M. Subpial siderosis of the central nervous system. Acta Neuropathol 1965;74:559-62.

15 Hughes JT, Oppenheimer DR. Superficial siderosis of the central nervous system. Acta Neuropathol 1969;13: 56-74.

16 Koeppen AH, Barron KD. Superficial siderosis of the central nervous system. J Neuropathol Exp Neurol 1971;30:448-69.

17 Koeppen AHW, Dentinger MP. Brain hemosiderin and superficial siderosis of the central nervous system. $J$ Neuropathol Exp Neurol 1988;47:249-70.

18 Lillie RD. Histopathological Technic and Practical Histochemistry. 3rd edn. New York: Blakiston, 1965: $388-428$

19 Pearse AGE. Histochemistry. 3rd edn. London: Churchill-Livingstone, 1972:1069, 1402.

\title{
Encephalitis lethargica
}

"Marie and Levy (Revue Neurologique, 1920) have drawn attention to a group of cases in which the musculature of the face, tongue, jaws, and pharynx is especially affected by the occurrence of either involuntary movements or hypertonus. In these patients there may be clonic contractions of muscles or parts of muscles, or rhythmic tremors of antagonistic groups, which in the case of the jaw muscles may result in chattering of the teeth. In certain cases trismus has been observed."

Symonds, CP. Encephalitis lethargica. Q J Med 1921;55:283-308.

RT ROSS

\section{Pink disease}

"There is a clinical entity ... common in the second year of life which presents the following characteristics:

(a) Erythroedema: coldness, redness, swelling of the hands, feet, cheeks, and nose with desquamation.

(b) Perspiration of the whole body ... with a mouse-like odour and falling out of the hair.

(c) Extreme mental misery, irritability, insomnia, and obstinate anorexia.

(d) Muscular hypotonia, loss or diminution of tendon reflexes, and relative or absolute anasthesia."

Donald Paterson and J Godwin Greenfield. Erythroedema polyneuritis (the so-called “Pink Disease”). QJ Med 1923;65:6-18.

RT ROSS

\section{Encephalitis in children}

"From a study of $\mathbf{4 0}$ cases of encephalitis lethargica in childhood we have come to regard disturbances of sleep sequence, psychical changes, and the development of troublesome habits as the most frequent sequelae. Chorea, ... developed during the acute stages of the disease ... tended to recur in combination with various sequelae for long periods after apparent recovery. Paralysis of cranial nerves was not uncommon during the acute illness, but never recurred ... . Parkinsonian tremor developed in only one case (from a study of 40 cases), but a mask-like expression, . . accompanied by slow scanning speech without other symptoms of paralysis agitans was of frequent occurrence."

Grace $\mathrm{H}$ Anderson. The sequelae of epidemic encephalitis in childhood with notes on the prognosis as regards complete recovery. $Q J$ Med 1923;63:173-92.

RT ROSS

\section{Periosteal neurofibromatosis}

“The famous 'elephant man' (Merrick), whom I once saw, and who died at the London Hospital at the age of 27 years (on April 11, 1890) had many deformities of the nature of pachydermatoceles as well as many boney thickenings and outgrowths. There was no post-mortem examination, but a regular periosteal neurofibromatosis may well have played a part in his osseous deformities.

Periosteal neurofibromatosis . . . hardly recognized as such until Brooks and Lehman drew attention to the subject in 1924 ... is probably present in all the cases roughly grouped together as neurofibromatosis elephantiasis of limbs, especially those which show definite excess in bone length. Such cases are apparently nearly always unilateral."

Parkes Weber, F. Periosteal neurofibromatosis, with a short consideration of the whole subject of neurofibromatosis. $Q J M e d$ 1929;23:151-66. 